\title{
A HIGH RESOLUTION OPTICAL DATING STUDY OF THE MOSTIŞTEA LOESS-PALAEOSOL SEQUENCE (SE ROMANIA) USING SAND-SIZED QUARTZ
}

\author{
Ş. VASILINIUC ${ }^{1,2}$, A. TIMAR-GABOR ${ }^{1}$, D.A.G. VANDENBERGHE ${ }^{2}$, C.G. PANAIOTU ${ }^{3}$, R. CS. BEGY ${ }^{1}$ \\ and C. COSMA ${ }^{1}$ \\ ${ }^{I}$ Faculty of Environmental Science, Babes-Bolyai University, Fântânele 30, 400294 Cluj Napoca, Romania \\ ${ }^{2}$ Laboratory of Mineralogy and Petrology (Luminescence Research Group), Department of Geology and Soil Science, Ghent Univer- \\ sity, Krijgslaan 281 (S8), B-9000 Ghent, Belgium \\ ${ }^{3}$ Faculty of Physics, Paleomagnetic Laboratory, University of Bucharest, N. Bălcescu 1, 010041 Bucharest, Romania
}

Received 18 June 2010

Accepted 20 October 2010

\begin{abstract}
We report on SAR-OSL dating of closely-spaced samples from the loess-palaeosol sequence near Mostiştea lake (Danube Plain, SE Romania). We used sand-sized quartz and a SAR protocol that involved a preheat of $10 \mathrm{~s}$ at $220^{\circ} \mathrm{C}$ and a test dose cutheat to $180^{\circ} \mathrm{C}$. It is shown that these thermal pretreatments isolate a quartz OSL signal that is dominated by the fast component. The behaviour of this signal in the SAR protocol is then documented. The ratio of the measured to given dose tends to lie slightly but systematically above unity ( $\sim 5 \%$ on average) and the recycling ratio below unity ( $\sim 6 \%$ on average); for all samples, the recuperated signal is negligible. Within analytical uncertainty, the nineteen optical ages are internally consistent and agree with the predictions from a palaeomagnetic age-depth model. Although it may be possible to optimize the SAR measurement procedure, the optical ages already confirm the chronostratigraphic position of the uppermost welldeveloped palaeosol in that it formed during MIS 5. The established chronology allows correlating the sequence near Mostiştea lake with that near Mircea Vodă that we investigated earlier.
\end{abstract}

Keywords: optical dating; 63-90 $\mu \mathrm{m}$ quartz; loess, Romania, high resolution.

\section{INTRODUCTION}

Loess and loess-like deposits are widespread along the lower Danube river. In Romania, they cover mainly the southern and southeastern part of the country (Conea, 1970). The deposits can be up to $\sim 50 \mathrm{~m}$ thick and contain several well-developed palaeosols. The Romanian loesspalaesol sequences are thought to represent continuous and extended archives of regional climatic and environmental change during the Late and Middle Pleistocene and they help to improve our understanding of the link between similar deposits in Europe and Asia. So far, the chronology of Romanian loess has been mainly based on relative methods (such as pedostratigraphy and magnetic susceptibility) and correlation of successions with comparable features (see e.g. Conea, 1969 and 1970; Panaiotu et al., 2001). It has been demonstrated that the assumptions underlying proxy-based age models (such as continuous sedimentation) can be inaccurate (see e.g. Stevens et al., 2007). Because an absolute timeframe is lacking, there is great uncertainty about the stratigraphic position of several palaeosols and the way in which they should be correlated. This strongly hampers interpreting the sequences in terms of the signatures of palaeoclimatic and environmental changes.

Corresponding author: S. Vasiliniuc

e-mail: stef.vasiliniuc@ubbcluj.ro 
For several decades, loess deposits have been intensively investigated using luminescence dating techniques (see e.g. the overview by Roberts, 2008, and references therein). As far as Romanian loess is concerned, however, the method seems to have seen only little application. Balescu et al. $(2003 ; 2010)$ used infrared stimulated luminescence (IRSL) signals from coarse silt-sized alkali feldspars to establish a broad chronological framework for the loess-palaeosol units exposed at three sections (Tuzla, Mircea Vodă, and near Mostiştea lake; Fig. 1). Despite the limited dataset, these studies demonstrated that, at the three investigated localities, the uppermost well-developed palaeosol (S1) formed during MIS 5. The most robust luminescence dating procedure currently available involves the use of optically stimulated luminescence (OSL) signals from quartz, in combination with the single-aliquot regenerative-dose (SAR) protocol (Murray and Olley, 2002; Wintle and Murray, 2006). Timar et al. (2010a) took this approach in a high resolution study of the section near Mircea Vodă. SAR-OSL dating of silt-sized $(4-11 \mu \mathrm{m})$ quartz confirmed the chronostratigraphic position of the S1 unit (i.e. MIS 5) and demonstrated that loess accumulation rates have varied during the Last Glacial. Timar et al. (2010b) subsequently applied SAR-OSL dating to sand-sized quartz extracted from the same samples; this yielded ages that were in between $20-70 \%$ higher than those obtained on the fine grains. Nevertheless, both sets of ages confirmed that the S1 unit corresponds to MIS 5; they conflict, however, as to how an overlying weakly-developed soil horizon should be interpreted (MIS 3 or MIS 5?). Although methods to correct IRSL signals from feldspar for anomalous fading (as was done by Balescu et al., 2003; 2010) are contentious, especially for older samples with De's > $\sim 150-200 \mathrm{~Gy}$, and the discrepancy between the SAROSL ages for silt and sand-sized quartz remains to be resolved, both dosimeters challenge the long-held assumption that the S1 palaeosol was formed during an interstadial of the Last Glacial period (Conea, 1969).

The present study focuses on the SAR-OSL characteristics and age of sand-sized quartz extracted from the loess-palaeosol sequence near Mostiştea lake (Danube Plain, SE Romania). Our investigations of Romanian loess frame in a larger research project that aims at establishing an accurate and precise chronology for European loess deposits.

\section{STUDY SITE AND SAMPLING}

The investigated loess-palaeosol sequence is located on the border of Mostiştea lake $(\sim 20 \mathrm{~km}$ in length and $56.7 \mathrm{~km}^{2}$ of water surface, Danube Plain, SE Romania; Fig. 1). It is about $21 \mathrm{~m}$ thick and consists of four loesspalaeosol units (L1, S1 etc.) and the Holocene topsoil (S0). The Mostiştea loess-palaeosol sequence has previously been investigated using magnetic susceptibility (MS) and IRSL techniques (Panaiotu et al., 2001; 2004;
Necula and Panaiotu, 2008; Balescu et al., 2010). Both the MS and the IRSL results indicate that the uppermost three palaeosols (S1, S2, S3) formed during MIS5, MIS 7 and MIS 9, respectively.

The profile investigated here is located at a distance of $\sim 50 \mathrm{~m}$ from the previously studied sections. Our study focused on the uppermost loess-palaeosol unit $(\mathrm{L} 1 / \mathrm{S} 1)$ and the top of the second loess unit (L2). Due to intense bioturbation in the form of rootcasts and the difficult access to the upper part of the L1 unit, the samples were collected starting from a depth of $2.1 \mathrm{~m}$. Nineteen samples in total were collected, at relatively closely spaced vertical intervals $(\sim 10-25 \mathrm{~cm}$; Fig. 2). The sampling was performed by hammering stainless steel cylinders in

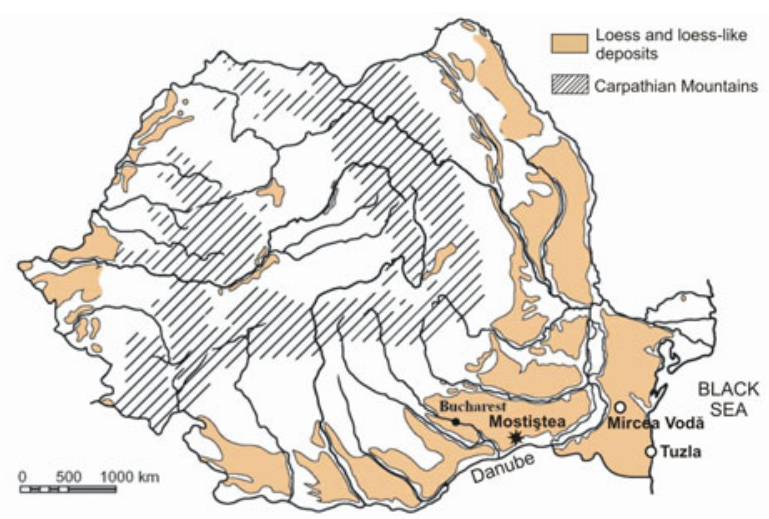

Fig. 1. Map showing the location of the sampling site (Mostiştea); the location of the sections near Mircea Vodă and the Black Sea shore (Tuzla) is indicated as well.

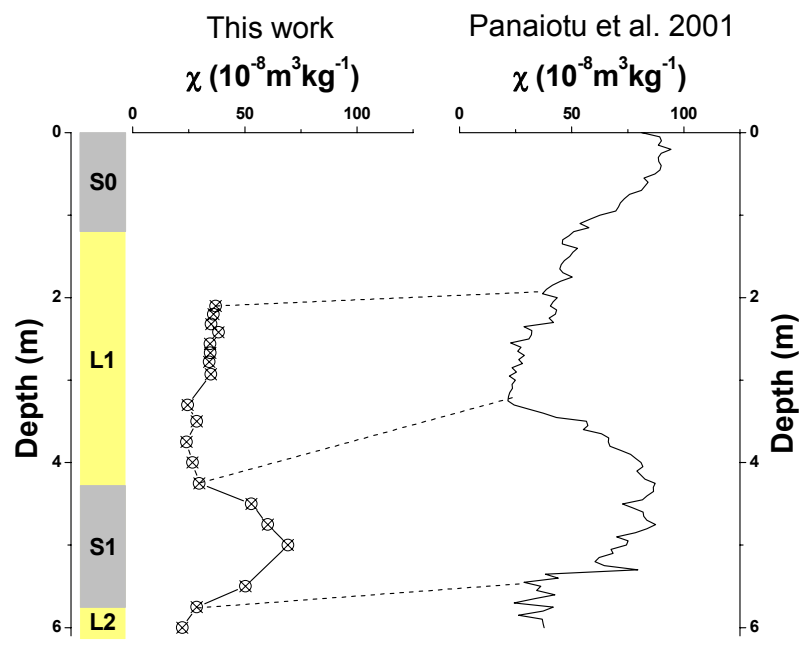

Fig. 2. The variation of the magnetic susceptibility measured for subsamples of sediment surrounding the OSL tubes (left) is correlated with that in the section previously investigated by Panaiotu et al. (2001) (right). The dashed lines (eye guides) indicate this correlation. 
freshly cleaned exposures. The sediment surrounding each tube was collected for dose rate determination. To correlate our sections with those from the previous studies, the magnetic susceptibility was measured using a MS2B Magnetic Susceptibility System (Bartington Instruments) on a subsample of the sediment surrounding each OSL tube (Fig. 2).

\section{SAMPLE PREPARATION AND ANALYTICAL FACILITIES}

Sand-sized $(63-90 \mu \mathrm{m})$ quartz grains were extracted from the inner material of the sampling tubes using conventional (Lang et al., 1996; Mauz et al., 2002) sample preparation techniques $\left(10 \% \mathrm{HCl}, 30 \% \mathrm{H}_{2} \mathrm{O}_{2}\right.$, wet sieving, density separation using heavy liquids, $40 \% \mathrm{HF}$ ). For measurement, a monolayer of quartz grains was spread out on the inner $9 \mathrm{~mm}$ of $9.7 \mathrm{~mm}$-diameter stainless steel discs; silicone oil was used as adhesive. The purity of the quartz was confirmed by the absence of a significant IRSL response at $60^{\circ} \mathrm{C}$ to a large regenerative dose $(\sim 35$ Gy); the sensitivity to infrared stimulation was defined as significant if the OSL IR depletion ratio deviated more than $10 \%$ from unity (Duller, 2003). The test was performed for each aliquot that was measured; no aliquots had to be rejected on the basis of this criterion.

All luminescence measurements were made with a Risø TL/OSL DA-20 reader equipped with blue diodes emitting at $470 \pm 30 \mathrm{~nm}$ and IR LEDs emitting at 870 $\mathrm{nm}$; luminescence signals were observed through a 7.5 $\mathrm{mm}$ thick Hoya U-340 UV filter. Details on the measurement apparatus can be found in Bøtter-Jensen et al. (2003) and Thomsen et al. (2008).

The luminescence characteristics of the samples were investigated using the single-aliquot regenerative-dose (SAR) protocol (Murray and Wintle, 2000). Stimulation with the blue diodes was for $40 \mathrm{~s}$ at $125^{\circ} \mathrm{C}$. The first 0.32 $\mathrm{s}$ of the decay was used in the calculations, minus a background evaluated from the $1.60 \mathrm{~s}$ to $2.88 \mathrm{~s}$ interval. Moving the background interval closer to the initial signal is more effective in reducing the contribution from slower components (see e.g. Ballarini et al., 2007), but we observed no dependence of the results on the interval chosen for background evaluation. Unless indicated otherwise, natural and regenerated signals were measured after a preheat of $10 \mathrm{~s}$ at $220^{\circ} \mathrm{C}$; the response to the test dose $(17.3 \mathrm{~Gy})$ was measured after a cutheat to $180^{\circ} \mathrm{C}$. Timar et al. $(2010 \mathrm{a} ; 2010 \mathrm{~b})$ used the same thermal pretreatments in their optical dating studies of the loess section near Mircea Vodă. After the measurement of the response to the test dose, a high-temperature bleach was performed by stimulating with the blue diodes for $40 \mathrm{~s}$ at $280^{\circ} \mathrm{C}$ (Murray and Wintle, 2003).

For the determination of the annual dose, the sediment from the surroundings of the OSL tubes was dried, powdered and packed in sealed containers. The sediment samples were stored for at least one month before being measured using high-resolution gamma-ray spectrometry.

\section{LUMINESCENCE CHARACTERISTICS}

All quartz samples exhibit bright OSL signals that decay rapidly with stimulation time (Fig. 3). The decay is typical for quartz that is dominated by a fast component. This was confirmed by examining the LM-OSL signal of samples MST1, MST2 and MST12. The natural and regenerated signals show a well-defined peak early in the curve; the position of the peak matches that observed for calibration quartz and is not dependent on the preheat treatment (inset to Fig. 3, for sample MST2; samples MST1 and MST12 exhibit the same LM-OSL characteristics). It is generally accepted that the OSL signal of calibration quartz is dominated by the fast component.

A representative growth curve for an aliquot of sample MST2 is shown in Fig 4a. The growth of the signal with dose is best represented by the sum of two saturating exponential functions. Fig. 4a also illustrates the behaviour of the samples in the SAR protocol; sensitivity changes occurring throughout the measurement procedure are accurately corrected for (as indicated by recycling ratios ranging within 0.90-1.10) and the growth curves pass very close to the origin (as indicated by recuperation values well below $1 \%$ of the corrected natural OSL signal).

Fig. $4 \mathrm{~b}$ shows the average dose response curves for samples collected at various burial depths. All growth curves can be represented well by the sum of two saturating exponential functions. We observed no systematic variation in saturation characteristics with burial depth. $\mathrm{D}_{0}$ values for the early saturating exponential component

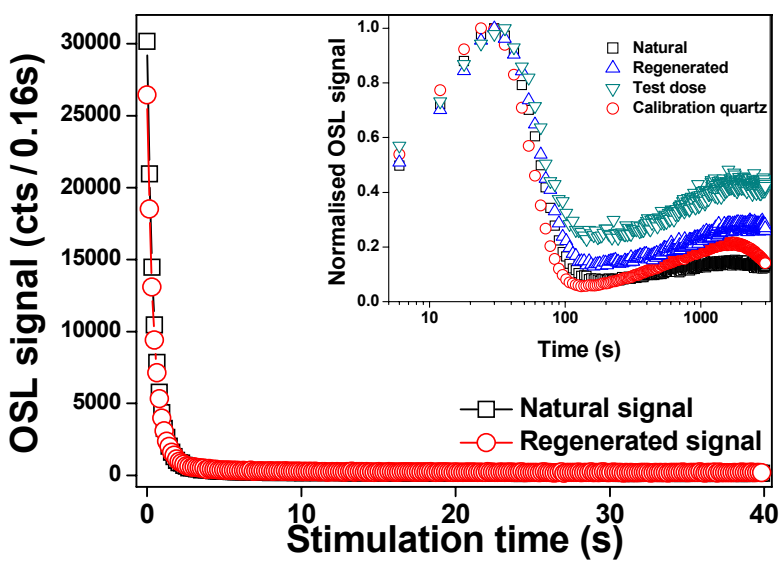

Fig. 3. Example of a natural and a regenerated OSL decay curve for one aliquot of sample MST2. The inset shows natural and regenerated LM-OSL signals for the same sample in comparison with calibration quartz. Stimulation power was ramped from 0 to $100 \%$ in $3000 \mathrm{~s}$. The natural, regenerated and calibration quartz luminescence signals were measured at $125^{\circ} \mathrm{C}$, following a preheat of $10 \mathrm{~s}$ at $220^{\circ} \mathrm{C}$. The test dose signal was measured at $125^{\circ} \mathrm{C}$, following a cutheat at $180^{\circ} \mathrm{C}$. 
(a)

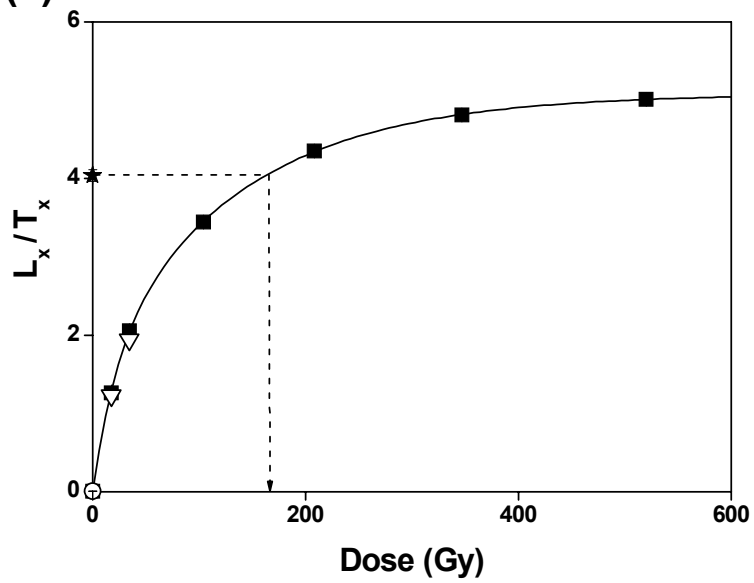

(b)

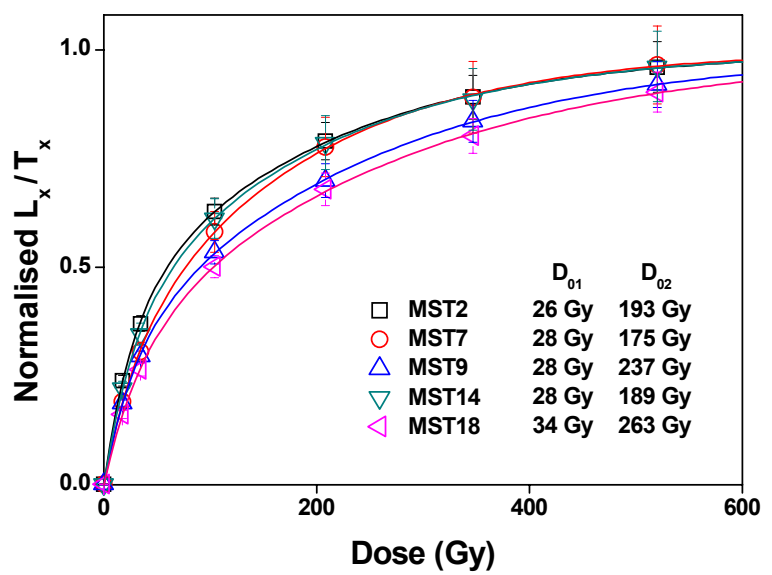

Fig. 4. (a) Example of a SAR growth curve for an aliquot of 63-90 $\mu \mathrm{m}$ quartz grains extracted from sample MST2. Recycled and recuperation points are shown as an open triangle and open circle, respectively. The solid line represents the best fit to the sum of two saturating exponential terms. (b) Average sensitivity corrected growth curves for nine samples of different age obtained using the sum of two saturating exponential functions: $I=A(1$ $\left.\exp \left(-\left(D+D_{a}\right) / D_{01}\right)\right)+B\left(1-\exp \left(-\left(D+D_{b}\right) / D_{02}\right)\right)$. The data are normalised to the sum of the saturation values $(A+B)$. Between 6 and 13 aliquots were measured for each sample. The saturation characteristics $\left(D_{01}, D_{02}\right)$ of each sample are given in the legend.

$\left(D_{01}\right)$ range from $\sim 26-40 \mathrm{~Gy}$, and for the slowly saturating exponential $\left(\mathrm{D}_{02}\right)$ from $\sim 175-303 \mathrm{~Gy}$.

Fig. 5a shows the dependence of equivalent dose $\left(D_{e}\right)$ on preheat temperature for sample MST2. Across the $200-280^{\circ} \mathrm{C}$ temperature range, all values are consistent with the average ( \pm 1 standard error) of $143 \pm 11$ Gy. Fig. 5b shows the corresponding recycling ratios and recuperation. The recycling ratio shows no variation with preheat temperature, but it has a tendency to lie below unity; the overall average value ( \pm 1 standard error) is $0.92 \pm 0.01$. The recuperated signal is negligible (as compared to the corrected OSL signal) across the entire investigated temperature range. The same observations were made for sample MST3.

To asses the suitability of the employed SAR protocol for measuring the dose in our samples, we performed a dose recovery test. At least four aliquots per sample were bleached at room temperature by stimulating for two times $40 \mathrm{~s}$ with the blue diodes; the two bleaching treatments were separated by a $10 \mathrm{ks}$ pause. The aliquots were then given a laboratory dose, which was chosen to be equal to the estimated equivalent dose $\left(D_{e}\right)$, and measured using the SAR protocol. Fig. 6a summarizes the dose recovery data. For only two samples, the measured to given dose ratio is consistent with unity within 1 standard error. When considering the $2 \sigma$ level, the ratio is consistent with unity for five samples and it is within $10 \%$ from unity for all samples, except MST9. For sample MST9, the measured to given dose ratio is $2.5 \pm 0.3$; at present, it is not understood as to why this particular sample behaves so differently from the other samples and yields such a poor dose recovery. At high given doses, the data can be more variable; this is not unexpected, given that (a)
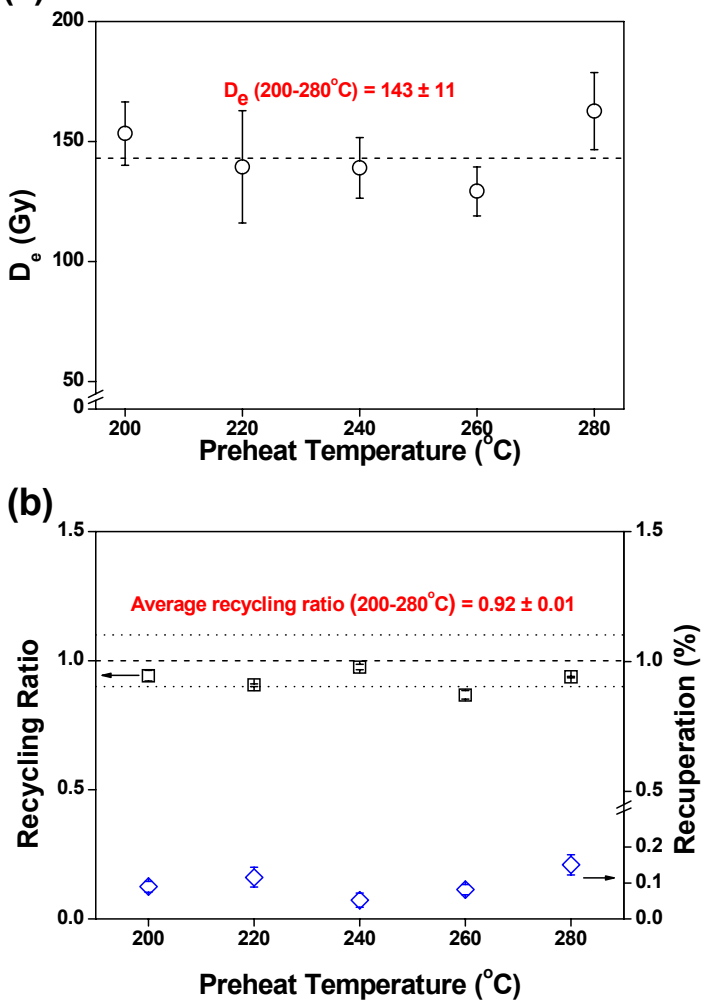

Fig 5. (a) Equivalent dose as a function of preheat temperature for sample MST2. A minimum of three aliquots was used per preheat temperature and the error bars represent one standard error. The dashed line (eye guide) highlights the average value across the 200$280^{\circ} \mathrm{C}$ preheat temperature interval. (b) Recycling ratios and recuperation as a function of preheat temperature for the same aliquots as in (a). Error bars represent one standard error. The dashed and dotted lines (eye guide) highlight the ideal recycling ratio of unity and $a \pm 10 \%$ deviation, respectively. 
(a)

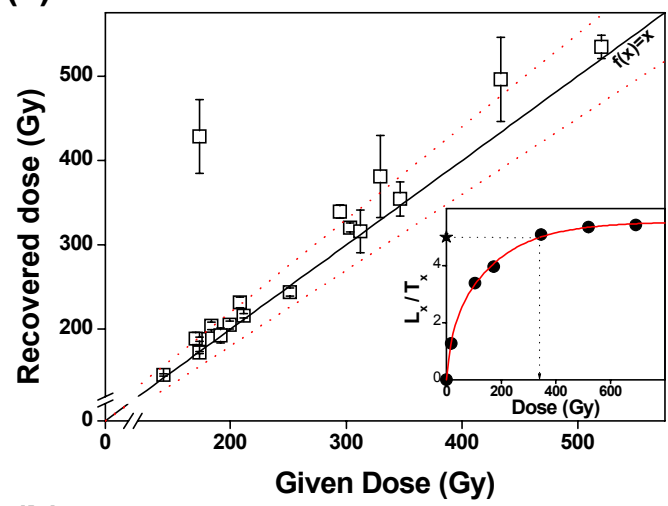

(b)

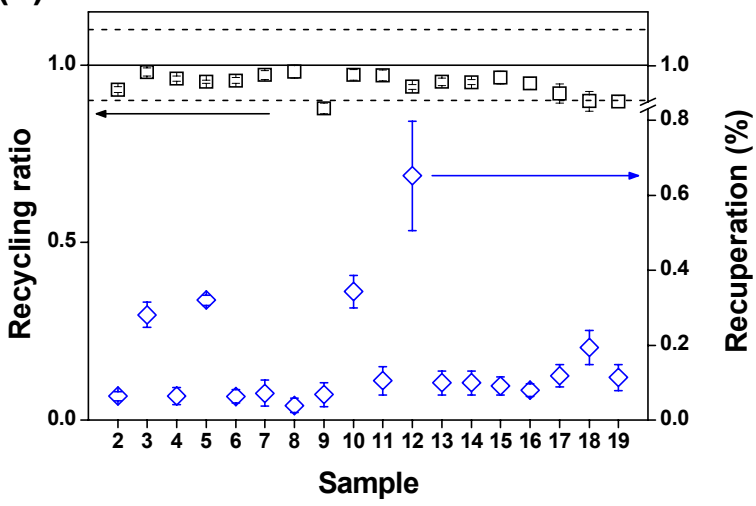

Fig. 6. (a) Results of the dose recovery test for all the investigated quartz samples. Each sample was given a dose approximately equal to the equivalent dose. A minimum of four aliquots was used per sample and error bars represent one standard error. The solid and dashed lines are the 1:1 relation and brackets of $10 \%$ deviation from unity, respectively. The inset shows an example of a sensitivity corrected growth curve for an aliquot of sample MST17. (b) Summary of the recycling ratios and recuperation for the same aliquots as in (a). Error bars represent one standard error. The dashed and dotted lines (eye guide) highlight the ideal recycling ratio of unity and $a \pm 10 \%$ deviation, respectively.

the resulting signals lie in the high dose region of the growth curve. (Fig. 6a, inset).

Excluding sample MST9, the average measured to given dose ratio ( \pm 1 standard error) is $1.045 \pm 0.002$ $(\mathrm{n}=45)$ for samples taken from the L1-unit, $1.09 \pm 0.01$ $(\mathrm{n}=26)$ for the ones from the S1-unit and $1.03 \pm 0.01$ $(n=5)$ for those from unit L2; there is no clear relation between the ability to recover a dose and the stratigraphic position of the samples, and the overall average measured to given dose ratio ( \pm 1 standard error) is $1.06 \pm 0.01$ $(\mathrm{n}=76)$. The corresponding recycling ratios and recuperation are presented in Fig. $\mathbf{6 b}$; excluding sample MST9, the overall average values ( \pm 1 standard error) are $0.948 \pm 0.004$ and $0.155 \pm 0.002 \%$, respectively. The values obtained in the three tests (recycling ratio, recuperation and dose recovery) are usually considered as acceptable in the literature. Nevertheless, the average recycling and measured to given dose ratios are slightly, but systematically, lower and higher than unity, respectively. This may indicate that sensitivity changes occurring at the beginning and/or throughout the measurement procedure are not entirely corrected for and that there may be an offset of $\sim 5 \%$ (on average). At this stage of our investigations, we considered these results acceptable, given that $D_{e}$ values must be obtained well up the dose-response curve (Fig. 4a, inset to Fig. 6a) and that the overall uncertainty on the luminescence ages amounts to $13-23 \%$ (see Section 6).

Table 1 summarizes the average $D_{e}$ values $( \pm 1$ standard error) that were obtained using the same SAR protocol as we previously used to date the section near Mircea Vodă (Timar et al., 2010a; 2010b). For each sample, in between 4 and 18 replicate measurements of $D_{e}$ were made. A value was accepted if both the recycling ratio and the IR depletion ratio were within $10 \%$ from unity, and if recuperation did not exceed $5 \%$ of the corrected natural signal. No aliquots had to be rejected on the basis of recuperation or impurity. Some aliquots, however, had to be rejected on account of a poor recycling. Especially for sample MST9, the correction for sensitivity changes appears rather problematic, as more than half of the aliquots had to be excluded from the analysis. The aberrant and poor luminescence behaviour of this particular sample had also been identified through the dose recovery test.

\section{DOSIMETRY}

Radionuclide activity concentrations were obtained through high-resolution gamma-ray spectrometry and converted to dose rates using the conversion factors calculated from the data presented by Adamiec and Aitken (1998). The external beta dose rates were corrected for the effects of etching and attenuation using a factor of 0.94 ( $\pm 5 \%$ relative uncertainty; Mejdahl, 1979). An internal dose rate of $0.013 \pm 0.003 \mathrm{~Gy} / \mathrm{ka}$ was assumed (Vandenberghe et al., 2008). A water content of $20 \pm 5 \%$ was used to account for the effect of moisture (Balescu et $a l ., 2003)$ and the contribution from cosmic radiation was calculated following Prescott and Hutton (1994). Table 1 summarizes the dosimetric information. It can be seen that there is little variation in dose rate with depth and the values are spread around a mean value $( \pm 1$ standard error) of $2.84 \pm 0.02 \mathrm{~Gy} / \mathrm{ka}$.

\section{OPTICAL AGES AND DISCUSSION}

All information relevant to the optical age and uncertainty calculation is summarized in Table 1. Uncertainties on the optical ages were calculated following the error assessment system proposed by Aitken and Alldred (1972) and Aitken (1976). In general, the systematic uncertainty is dominant in the overall uncertainty on the ages, which amounts to $13-24 \%$. The overall contribution 
Table 1. Summary of radionuclide activities, calculated total dose rates, equivalent doses $\left(D_{e}\right)$, optical ages, and random $\left(\sigma_{r}\right)$, systematic $\left(\sigma_{s y s}\right)$ and total (Got) uncertainties. The number of accepted aliquots out of the total measured is indicated in the subscript to the $D_{e}$-data. Uncertainties mentioned with the $D_{e}$ and dosimetry data are random; all uncertainties represent one sigma. The uncertainty associated with the water content $(20 \pm 5$ $\%)$ is dominant in the overall systematic uncertainty.

\begin{tabular}{|c|c|c|c|c|c|c|c|c|c|c|}
\hline Sample & $\begin{array}{l}\text { Depth } \\
\text { (cm) }\end{array}$ & $\begin{array}{c}{ }^{226} \mathrm{Ra} \\
\left(\mathrm{Bq} \mathrm{kg}{ }^{-1}\right)\end{array}$ & $\begin{array}{c}{ }^{232} \mathrm{Th} \\
\left(\mathrm{Bq} \mathrm{kg}^{-1}\right)\end{array}$ & $\begin{array}{c}{ }^{40} \mathrm{~K} \\
\left(\mathrm{~Bq} \mathrm{~kg}^{-1}\right)\end{array}$ & $\begin{array}{c}\text { Total } \\
\text { Dose Rate } \\
\text { (Gy / ka) }\end{array}$ & $\begin{array}{l}\mathrm{De} \\
\text { (Gy) }\end{array}$ & $\begin{array}{l}\text { Age } \\
\text { (ka) }\end{array}$ & $\begin{array}{c}\sigma_{r} \\
(\%)\end{array}$ & $\begin{array}{c}\sigma_{\text {sys }} \\
(\%)\end{array}$ & $\begin{array}{l}\sigma_{\text {tot }} \\
(\%)\end{array}$ \\
\hline MST 1 & 210 & $33 \pm 1$ & $40 \pm 1$ & $594 \pm 8$ & $2.85 \pm 0.03$ & $175 \pm 8(n=17 / 18)$ & $61 \pm 8$ & 4.7 & 12.8 & 13.6 \\
\hline MST 2 & 220 & $32 \pm 1$ & $41 \pm 1$ & $591 \pm 8$ & $2.84 \pm 0.03$ & $130 \pm 10_{(\mathrm{n}=7 / 10)}$ & $46 \pm 7$ & 7.4 & 12.8 & 14.8 \\
\hline MST 3 & 232 & $35 \pm 1$ & $41 \pm 1$ & $606 \pm 8$ & $2.93 \pm 0.03$ & $153 \pm 4_{(n=9 / 11)}$ & $52 \pm 7$ & 2.79 & 12.8 & 13.1 \\
\hline MST 4 & 242 & $32 \pm 1$ & $40 \pm 1$ & $625 \pm 6$ & $2.91 \pm 0.02$ & $162 \pm 18_{(n=8 / 8)}$ & $56 \pm 9$ & 11.2 & 12.8 & 17.0 \\
\hline MST 5 & 256 & $33 \pm 1$ & $41 \pm 1$ & $609 \pm 8$ & $2.90 \pm 0.03$ & $169 \pm 9_{(n=6 / 8)}$ & $58 \pm 8$ & 5.5 & 12.8 & 13.9 \\
\hline MST 6 & 267 & $32 \pm 1$ & $39 \pm 1$ & $612 \pm 9$ & $2.86 \pm 0.03$ & $185 \pm 9_{(n=15 / 15)}$ & $65 \pm 9$ & 5.0 & 12.8 & 13.8 \\
\hline MST 7 & 278 & $32 \pm 1$ & $41 \pm 1$ & $603 \pm 8$ & $2.86 \pm 0.03$ & $191 \pm 17_{(n=7 / 8)}$ & $67 \pm 11$ & 9.1 & 12.8 & 15.7 \\
\hline MST 8 & 293 & $34 \pm 1$ & $41 \pm 1$ & $605 \pm 8$ & $2.90 \pm 0.03$ & $186 \pm 12(n=10 / 13)$ & $64 \pm 9$ & 6.4 & 12.9 & 14.3 \\
\hline MST 9 & 330 & $31 \pm 1$ & $37 \pm 1$ & $593 \pm 8$ & $2.76 \pm 0.03$ & $260 \pm 28(n=5 / 17)$ & $94 \pm 16$ & 10.9 & 12.9 & 16.8 \\
\hline MST 10 & 350 & $31 \pm 1$ & $38 \pm 1$ & $576 \pm 6$ & $2.72 \pm 0.02$ & $210 \pm 16_{(n=5 / 5)}$ & $77 \pm 11$ & 7.5 & 12.9 & 14.9 \\
\hline MST 11 & 375 & $32 \pm 1$ & $37 \pm 1$ & $591 \pm 8$ & $2.76 \pm 0.03$ & $232 \pm 33(n=7 / 11)$ & $84 \pm 16$ & 14.5 & 12.9 & 19.4 \\
\hline MST 12 & 400 & $32 \pm 1$ & $39 \pm 1$ & $606 \pm 8$ & $2.83 \pm 0.03$ & $237 \pm 22(n=11 / 13)$ & $84 \pm 13$ & 9.4 & 12.9 & 16.0 \\
\hline MST 13 & 425 & $33 \pm 1$ & $41 \pm 1$ & $601 \pm 8$ & $2.86 \pm 0.03$ & $277 \pm 15(n=11 / 13)$ & $97 \pm 14$ & 5.5 & 12.9 & 14.0 \\
\hline MST 14 & 450 & $32 \pm 1$ & $40 \pm 1$ & $621 \pm 8$ & $2.88 \pm 0.03$ & $273 \pm 25_{(n=8 / 8)}$ & $95 \pm 15$ & 9.1 & 13.0 & 15.9 \\
\hline MST 15 & 475 & $32 \pm 1$ & $40 \pm 1$ & $618 \pm 9$ & $2.86 \pm 0.03$ & $253 \pm 38(n=3 / 6)$ & $88 \pm 18$ & 15.1 & 13.0 & 19.9 \\
\hline MST 16 & 500 & $31 \pm 1$ & $40 \pm 1$ & $589 \pm 8$ & $2.77 \pm 0.03$ & $275 \pm 51_{(n=6 / 10)}$ & $100 \pm 22$ & 18.5 & 12.9 & 22.6 \\
\hline MST 17 & 550 & $29 \pm 1$ & $38 \pm 1$ & $557 \pm 7$ & $2.63 \pm 0.02$ & $279 \pm 28(n=5 / 6)$ & $107 \pm 18$ & 10.2 & 12.9 & 16.5 \\
\hline MST 18 & 575 & $30 \pm 1$ & $38 \pm 1$ & $585 \pm 6$ & $2.70 \pm 0.02$ & $391 \pm 28(n=5 / 6)$ & $144 \pm 21$ & 7.2 & 13.0 & 14.9 \\
\hline MST 19 & 600 & $29 \pm 1$ & $38 \pm 1$ & $585 \pm 7$ & $2.69 \pm 0.02$ & $288 \pm 57(n=4 / 4)$ & $107 \pm 26$ & 20.0 & 13.0 & 23.8 \\
\hline
\end{tabular}

from random sources of uncertainty varies in between $\sim 3$ and $20 \%$. Within this uncertainty, most of the optical ages are consistent with the stratigraphic position of the samples and they increase smoothly with depth. At the $3 \sigma$ level, only sample MST1 yields an age that cannot be reconciled with the results obtained for the underlying samples, and, therefore, might be an outlier. Therefore, it is concluded that all sources of random uncertainty have been identified and properly accounted for, and that the observed variability is not much larger than expected from the individual uncertainties.

It is interesting to note that the optical age results do not seem to reflect a similar spread as observed in the dose recovery test (Fig. 6a). As pointed out by e.g. Timar et al. (2010a) and Murray et al. (2008), a dose recovery test is not necessarily a measure for the accuracy by which natural doses can be measured; this implies, as illustrated by our dataset, that it not necessarily provides a measure for the minimum variability that can be observed for an entire set of optical ages.

The optical ages are compared with the magnetic agedepth model established by Necula and Panaiotu (2008) in Fig. 7. No confidence limits can be defined for the agedepth model, but we incorporated a depth error of \pm 10 $\mathrm{cm}$ for the correlation between the sequence investigated here and the one for which the model was established. Within analytical uncertainty, the optical ages are consistent with the age model derived from the magnetic susceptibility data. Some spread can be observed in the OSL ages obtained for samples taken from the S1 unit (MST

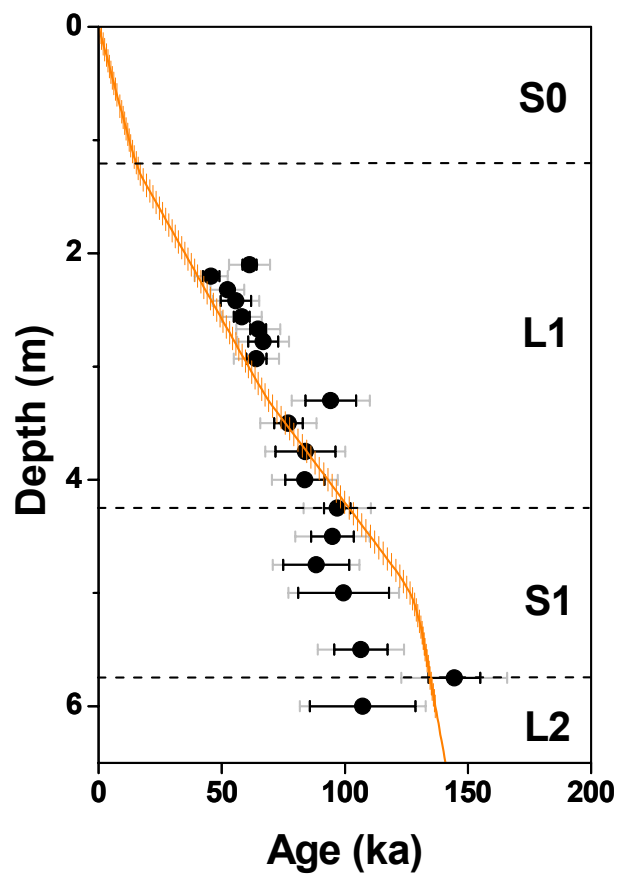

Fig. 7. Plot of optical ages (solid circles) as a function of depth; the magnetic age-depth model is shown by the solid line with error bars incorporating a depth error of $\pm 10 \mathrm{~cm}$ for the correlation between the section investigated here and the one for which the model was established (Necula and Panaiotu, 2008). The error bars associated with the optical ages represent $1 \sigma$ total uncertainties (grey bars) and $1 \sigma$ random uncertainties (black bars). The dashed lines (eye guide) highlight the boundaries of the stratigraphic units. 
13-18). As outlined in the previous section, the observed spread is not higher than expected from the random uncertainties associated with these age estimates, which range from $\sim 6$ to $\sim 19 \%$. This behaviour might be the effect of pedogenic processes such as bioturbation, although a significant contribution to the spread is also expected from the high value of the natural OSL on the dose-response curve which increases the uncertainty in equivalent dose (see Fig. 4 of Murray and Funder, 2003).

The SAR-OSL ages confirm the chronostratigraphic position of S1, in that it formed during MIS 5; this is also in accordance with the IRSL chronology established by Balescu et al. (2010) at this locality.

In general, the optical ages allow correlating the sequence near Moştistea lake with that near Mircea Vodă (Timar et al., 2010a; 2010b). At both localities, the L1/S1 sequence represents the Last Glacial/Interglacial cycle. The intense bioturbation that occurred at the top of L1 unit of the Mostiştea sequence lead to an indiscernible bedding structure, forcing the sampling to start from deeper down the section. Therefore the youngest age obtained for this unit is $\sim 45 \mathrm{ka}$. Based on the good correlation between the magnetic age-depth model and the OSL ages for the upper part of L1, it is deduced that the formation of this unit has ended at a comparable time as for the section near Mircea Vodă ( 16 ka BP).

For the studied sequence the loess deposition corresponding to the L1 unit seems to have occurred at two slightly different rates - a slower rate $(\sim 2.9 \mathrm{~cm} / \mathrm{ka})$ between $45-70 \mathrm{ka}$ and a faster rate $(\sim 7.2 \mathrm{~cm} / \mathrm{ka})$ between 70 and $90 \mathrm{ka}$. A change in the deposition rate was also observed for the section near Mircea Vodă, but to a higher extent $(3.5 \mathrm{~cm} / \mathrm{ka}$ and $25 \mathrm{~cm} / \mathrm{ka}$, respectively - Timar et al., 2010b).

\section{CONCLUSIONS}

It is concluded that the obtained set of quartz-based SAR-OSL ages confirms the chronostratigraphy of the loess-palaeosol sequence near Moştistea Lake as previously established through both IRSL dating and palaeomagnetic age modelling. The combined evidence conflicts with the chronostratigraphical framework proposed by Conea (1969), in that the S1 unit can no longer be thought of as a soil that developed during a Last Glacial interstadial. By extrapolation, the same holds for the underlying S2 unit.

The accuracy of SAR-OSL dating of sand-sized quartz extracted from Romanian loess remains to be established. In fact, the age discrepancy between SAR-OSL ages for fine silt and sand-sized quartz reported by Timar et al. (2010b; see Section 1) does raise concern as to the reliability of each of both grain-size fractions of this dosimeter. In this study, we only investigated the SAROSL properties and age of the sand-sized fraction. Procedural checks (recycling and dose recovery) indicate that the measurement procedure slightly, but systematically, overestimates a known laboratory dose that has been given to sample prior to any heating. We also observed, however, that a sample for which a poor dose recovery is achieved, not necessarily yields an aberrant age result as well (e.g. sample MST9). Therefore, SAR-OSL dating of (Romanian) loess using quartz may be more complicated than generally is assumed. Only in the presence of another form of a tight independent age control, which often lacks in loess, one can check whether this is important or not. Until then, the ages are probably the best chronological information currently available for this site.

Within the above-mentioned limitations, the results of this and our previous studies demonstrate that the approach allows establishing a broad chronological framework for Romanian loess-palaeosol records, assessing whether or not they are complete, and verifying if sediment accumulation occurred continuously and at a constant rate. As such, it is concluded that quartz-based SAR-OSL dating is a powerful tool to spatially and temporally correlate Romanian loess-palaeosol sequences, and to assess the validity of proxy-based methods for timing and reconstructing climatic and environmental change.

\section{ACKNOWLEDGEMENTS}

SV gratefully acknowledges financial support provided from programs co-financed by The SECTORAL OPERATIONAL PROGRAMME HUMAN RESOURCES DEVELOPMENT, Contract POSDRU 6/1.5/S/3 - Doctoral studies: through science towards society. Luminescence research of European loess at Ghent University (DV) is financed by the Fund for Scientific Research - Flanders (FWO - Vlaanderen). Magnetic measurements were supported by CNCSIS -UEFISCSU, project number PNII-IDEI 31/2010. Thanks to Mihai Gabor for the logistical support during the sampling campaign.

\section{REFERENCES}

Adamiec G and Aitken M, 1998. Dose-rate conversion factors: update. Ancient TL 16: 37-50.

Aitken MJ, 1976. Thermoluminescence age evaluation and assessment of error limits: revised system. Archaeometry 18(2): 233-238, DOI 10.1111/j.1475-4754.1976.tb00168.x.

Aitken MJ and Alldred JC, 1972. The assessment of error limits in thermoluminescence dating. Archaeometry 14(2): 257-267, DOI 10.1111/j.1475-4754.1972.tb00068.x.

Balescu S, Lamothe M, Mercier N, Huot S, Balteanu D, Billard A and Hus J, 2003. Luminescence chronology of Pleistocene loess deposits from Romania: testing methods of age correction for anomalous fading in alkali feldspars. Quaternary Science Reviews 22(10-13): 967-973, DOI 10.1016/S0277-3791(03)00056-8.

Balescu S, Lamothe M, Panaiotu C. and Panaiotu C, 2010. La chronologie IRSL des séquences loessiques de l'Est de La Roumanie. Quaternaire, in press.

Ballarini M, Wallinga J, Wintle AG, Bos AJJ, 2007. A modified SAR protocol for optical dating of individual grains from young quartz samples. Radiation Measurements 42(3): 360-369, DOI 10.1016/j.radmeas.2006.12.016. 
Bøtter-Jensen L, Andersen CE, Duller GAT and Murray AS, 2003. Developments in radiation, stimulation and observation facilities in luminescence measurements. Radiation Measurements 37(4-5): 535-541, DOI 10.1016/S1350-4487(03)00020-9.

Conea A, 1969. Profils de loess en Roumanie. La stratigraphy des loess d'Europe. In: Fink J, ed., Bulletin de l'Association Française pour l'étude du Quaternaire. Suppl. INQUA: 127-134.

Conea A, 1970. Formațiuni Cuaternare în Dobrogea (loessuri și paleosoluri) (Quaternary units in Dobrogea). Editura Academiei RSR, București: 234 pp (in Romanian).

Duller GAT, 2003. Distinguishing quartz and feldspar in single grain luminescence measurements. Radiation Measurements 37(2): 161165, DOI 10.1016/S1350-4487(02)00170-1.

Lang A, Lindauer S, Kuhn R, Wagner GA, 1996. Procedures used for optically and infrared stimulated luminescence dating of sediments in Heidelberg. Ancient TL 14: 7-11.

Mauz B, Bode T, Mainz E, Blanchard H, Hilger W, Dikau R and Zöller $\mathrm{L}, 2002$. The luminescence dating laboratory at the University of Bonn: equipment and dating procedures. Ancient TL 20(2): 53-61.

Mejdahl M, 1979. Thermoluminescence dating: beta dose attenuation in quartz grains. Archaeometry 21(1): 61-72, DOI 10.1111/j.14754754.1979.tb00241.x.

Murray AS and Funder S, 2003. Optically stimulated luminescence dating of a Danish Eemian coastal marine deposit: a test of accuracy. Quaternary Science Reviews 22(10-13): 1177-1183, DOI 10.1016/S0277-3791(03)00048-9.

Murray AS and Olley JM, 2002. Precision and accuracy in the optically stimulated luminescence dating of sedimentary quartz: a status review. Geochronometria 21: 1-16.

Murray AS and Wintle AG, 2000. Luminescence dating of quartz using an improved single-aliquot regenerative-dose protocol. Radiation Measurements 32(1): 57-73, DOI 10.1016/S1350-4487(99)00253$\mathrm{X}$.

Murray AS and Wintle AG, 2003. The single aliquot regenerative dose protocol: potential for improvements in reliability. Radiation Measurements 37(4-5): $\quad 377-381, \quad$ DOI $\quad 10.1016 / \mathrm{S} 1350-$ 4487(03)00053-2.

Murray AS, Buylaert JP, Henriksen M, Svendsen JI and Mangerud J, 2008. Testing the reliability of quartz OSL ages beyond the Eemian. Radiation Measurements 43(2-6): 776-780, DOI 10.1016/j.radmeas.2008.01.014

Necula C and Panaiotu C, 2008. Application of dynamic programming to the dating of a loess-palaesol sequence. Romanian Reports in Physics 60: 157-171.

Panaiotu CG, Panaiotu EC, Grama A and Necula C, 2001. Paleoclimatic record from loess-paleosol profile in Southeastern Romania. Physics and Chemistry of the Earth A 26(11-12): 893-898, DOI 10.1016/S1464-1895(01)00138-7.

Panaiotu CE, Balescu S, Lamothe M, Panaiotu CG, Necula C and Grama A, 2004. Astronomical and luminescence dating of Lower Danubian loess (Romania). Geophysical Research Abstracts 6: 02900.

Prescott JR and Hutton JT, 1994. Cosmic ray contributions to dose rates for luminescence and ESR dating: large depths and long-term time variations. Radiation Measurements 23(2-3): 497-500, DOI 10.1016/1350-4487(94)90086-8

Roberts HM, 2008. The development and application of luminescence dating to loess deposits: a perspective on the past, present and future. Boreas 37(4): 483-507, DOI 10.1111/j.15023885.2008.00057.x.

Stevens T, Thomas DSG, Armitage SJ, Lunn HR, Lu H, 2007. Reinterpreting climate proxy records from Late Quaternary Chinese loess: A detailed OSL investigation. Earth-Science Reviews 80(1-2): 111-136, DOI 10.1016/j.earscirev.2006.09.001

Thomsen KJ, Bøtter-Jensen L, Jain M, Denby PM and Murray AS, 2008. Recent instrumental developments for trapped electron dosimetry. Radiation Measurements 43(2-6): 414-421, DOI 10.1016/j.radmeas.2008.01.003.

Timar A, Vandenberghe D, Panaiotu EC, Panaiotu CG, Necula C, Cosma $\mathrm{C}$ and Van den haute P, 2010a. Optical dating of Romanian loess using fine-grained quartz. Quaternary Geochronology 5(23): 143-148, DOI 10.1016/j.quageo.2009.03.003.

Timar Gabor AI, Vandenberghe DA, Vasiliniuc S, Panaiotu CE, Panaiotu CG, Dimofte D, Dimofte D and Cosma C, 2010b. Optical dating of Romanian loess: a comparison between sand-sized and silt-sized quartz. Quaternary International: accepted for publication.

Vandenberghe D, De Corte F, Buylaert J-P, Kučera J and Van den haute $\mathrm{P}, 2008$. On the internal radioactivity in quartz. Radiation Measurements 41(7-8): 768-773, DOI 10.1016/j.radmeas.2006.06.010.

Wintle AG and Murray AS, 2006. A review of quartz optically stimulated luminescence characteristics and their relevance in singlealiquot regeneration dating protocols. Radiation Measurements 41(4): 369-391, DOI 10.1016/j.radmeas.2005.11.001. 